\title{
Las cortinas de Favonio y la caza de amor de Acis (Góngora, Polifemo, XXVII, 213-216)*
}

\author{
ISABEL ROMÁN GUTIÉRREZ \\ Universidad de Sevilla
}

Título: Las cortinas de Favonio y la caza de amor de Acis (Góngora, Polifemo, XXVII, 213-216)

Resumen: El análisis de la férrea estructura de la Fábula de Polifemo y Galatea gongorina entendida como poema narrativo (organización de las secuencias, conexiones, paralelismos, simetrías, focalización narrativa) permite desvelar el sentido de pasajes que, sin ser considerados "reacios", adolecían de cierta ambigüedad interpretativa. Es el caso de la segunda mitad de la estrofa XXVII, tradicionalmente relacionada con Galatea, cuya lectura en función de la estrategia amorosa desplegada por Acis da cuenta de la extraordinaria precisión gongorina y enriquece notablemente la significación de la escena de la seducción al dar cabida, junto con el tema de la batalla amorosa, al no menos tradicional de la "caza de amor". La mención del viento Favonio, entendido ahora como cómplice del cazador, expresa indirectamente la maniobra de ocultamiento, necesaria en la secuencia, que se perdía en anteriores interpretaciones de la octava.

Palabras clave: Góngora, Polifemo, Estructura, Favonio, Acis.

Fecha de recepción: 25/6/2016.

Fecha de aceptación: 8/7/2016.
Title: The Favonio's Curtains and the Love Hunt of Acis (Góngora, Polifemo, XXVII, 213-216)

Abstract: Góngora's Fábula de Polifemo y Galatea has always been acknowledged as a narrative piece of poetry. However, to account for its rigid structure discloses the significance of places. 'Reluctant' to any interpretative ambiguity though they may seem, these places are, on the contrary, featured by it. A case in point is the second half of verse XXVII, traditionally related to Galatea. If attention is paid to the loving strategy carried out by Acis, its reading not only shows Gongora's extraordinary accuracy but it also notably enriches the meaning of the scene when seduction takes place. That is to say, beside the traditional topic of the battle of love 'love hunt' can also be found. Favonio, the wind, the hunter's accomplice, indirectly expresses the hiding ploy, in any case needed in the sequence but non-existent in previous interpretations of the scene.

Key words: Góngora, Polifemo, Structure, Favonio, Acis.

Date of Receipt: 25/6/2016.

Date of Approval: 8/7/2016.

* El presente trabajo forma parte del proyecto "Del sujeto a la institución literaria en la Edad Moderna: procesos de mediación” (FFI2014-54367-C2-2-R) del MINECO. 
En los últimos años, la Fábula de Polifemo y Galatea gongorina ha sido objeto de análisis que insisten en su condición de poema narrativo. A la zaga de Robert Jammes, que ya advirtió acerca de la composición geométrica, la "arquitectura sólida y potente" de la fábula (cuyos elementos están cuidadosamente seleccionados y ligados con la intención de distanciarse de Ovidio tanto en la inventio como en la dispositio) ${ }^{2}$, se han detenido en la solidez de su estructura, entre otros, Enrica Cancelliere, Thomas E. Peterson, Giulia Poggi, Giuseppe Mazzocchi, Maria Cristina Cabani, José María Pozuelo, Jesús Ponce Cárdenas, José Manuel Rico y Gerhard Poppenberg ${ }^{3}$.

2 Robert Jammes, La obra poética de don Luis de Góngora y Argote, Madrid, Castalia, 1987 [1967], pp. 475-482. Para Jammes, el poema está dividido en "tres cuerpos de dimensiones sensiblemente iguales: el ambiente (el Cíclope, su gruta, la Sicilia fértil o estéril — reflejo de la belleza de Galatea-), los amores de Acis y de Galatea, el canto de Polifemo", secuencias que llevan precisas señales de inicio. Indicó también las variaciones de la inventio con respecto a Ovidio: a Góngora no le atrae de Polifemo tanto el monstruo como el enamorado; tampoco atiende a la detallada descripción de la metamorfosis de Acis, que ahora es solo un eco: lo que le interesa de verdad es la historia amorosa de Acis y Galatea, justamente lo que Ovidio no había desarrollado. Los episodios secundarios, además (la adoración que sienten los habitantes de la isla hacia Galatea, la hospitalidad de Polifemo con el náufrago genovés) cobran sentido en función de la metamorfosis que sufren por amor tanto el temible cíclope como la esquiva ninfa.

3 Enrica Cancelliere, Góngora. Percorsi della visione, Palermo, Flaccovio Editore, 1990, pp. 159-169 (traducción española: Góngora. Itinerarios de la visión, Córdoba, Diputación Provincial, 2006, pp. 155-165); Thomas E. Peterson, "The Generation of Mythic Language in the Polifemo", Journal of Hispanic Philology, 17 (1993), 191-211 (p. 196); Giulia Poggi, "Mi voz por dulce, cuando no por mía: Polifemo entre Góngora y Stigliani”, en Góngora Hoy VII. El "Polifemo”, ed. Joaquín Roses, Córdoba, Diputación Provincial, 2005, pp. 53-74 (pp. 70-74); Giuseppe Mazzocchi, "La estructura narrativa del Polifemo", en Góngora Hoy VII. El "Polifemo", pp. 125-138; Maria Cristina Cabani, El gran ojo de Polifemo. Visión y voyeurismo en la tradición barroca de un mito clásico, anejo LXVII de Analecta Malacitana, Málaga, Universidad de Málaga, 2007, pp. 43-48 (al igual que Poggi, estudia Cabani el Polifemo gongorino en relación con el de Stigliani); José María Pozuelo Yvancos, "La Fábula de Polifemo y Galatea como poema narrativo", en Philologica (Homenaje al profesor Ricardo Senabre Sempere), Cáceres, Universidad de Extremadura, 1996, pp. 
Es, sin embargo, Pozuelo Yvancos quien llama la atención sobre la radical novedad gongorina: una organización del discurso que no depende únicamente de los elementos de la inventio ni de la dimensión estética y expresiva del verso y las estrofas, "criaturas casi autónomas, perfectas construcciones de sonido y de sentido", aspecto este que había privilegiado la crítica precedente. Góngora renueva el desarrollo de la fábula no solo con respecto a su modelo clásico, Ovidio, sino también en relación con formulaciones posteriores (entre otras, bien conocidas, las de Stigliani, Marino o Carrillo y Sotomayor $\left.{ }^{4}\right)$, enriqueciendo la inventio con nuevos motivos, añadiendo nuevas "ideas", pero, sobre todo, cuidando la dispositio textual y ofreciendo una elaboradísima estructura narrativa, de tal modo que, en palabras de Pozuelo, "una de las más altas cualidades de su poema es la dimensión estética de su organización narrativa en orden a una tensión cuidadosamente orquestada". Todos los elementos del relato están firmemente ligados entre sí en la medida en que "esta fábula es también una fábula (muthos) en el sentido aristotélico: un entramado de acciones solidarias, una intriga narrativa"s.

435-460 (también en La invención literaria. Garcilaso, Góngora, Cervantes, Quevedo y Gracián, Salamanca, Universidad de Salamanca, 2014, pp. 25-40); Jesús Ponce Cárdenas (ed.), Luis de Góngora, Fábula de Polifemo y Galatea, Madrid, Cátedra, 2010, pp. 62-71, y El tapiz narrativo del "Polifemo". Eros y elipsis, Barcelona, Universitat Pompeu Fabra, 2010; José Manuel Rico García, "Una aproximación al Polifemo a través de la crítica", en Góngora y su estela en la poesía española e hispanoamericana. El "Polifemo" y las "Soledades" en su IV centenario, ed. Antonio Castro Díaz, Sevilla I Córdoba, Asociación Andaluza de Profesores de Español "Elio Antonio de Nebrija" / Diputación Provincial, 2014, pp. 55-80 (pp. 66-71); Gerhard Poppenberg, "La Arcadia en la Fábula de Polifemo y Galatea de Góngora”, trads. Laura Selva Carugati y Rafael Bonilla Cerezo, Creneida, 3 (2008), pp. 210-260, finalmente, estructura la Fábula en función de la organización conceptual del mito arcádico.

4 Ni Stigliani ni Marino incluyen entre sus motivos la seducción amorosa. Stigliani se centra en el canto patético del monstruo enamorado; por lo que a Marino se refiere, puede verse ahora una especificación de sus motivos en el trabajo de Rafael Bonilla Cerezo y Linda Garosi, "Con arguta sambuca il fier semblante: la Polifemeida de Giovan Battista Marino", en La hidra barroca. Varia lección de Góngora, eds. Rafael Bonilla Cerezo y Giuseppe Mazzocchi, Córdoba, Junta de Andalucía, 2008, pp. 181-218 (pp. 191-192), que incluye una espléndida traducción de las Rime de Marino por parte de Bonilla Cerezo.

5 José María Pozuelo Yvancos, op. cit., pp. 437-438 y 444. 
Hay unanimidad crítica con respecto a la importancia concedida por Góngora a la narración del proceso amoroso entre Acis y Galatea, que ocupa una parte bien extensa del poema (XXXIII-XLII) y que, como sabemos, no era capital ni en el modelo ovidiano ni en posteriores versiones. Sin duda, es uno de los motivos de la inventio gongorina con los que el cordobés busca la distinción con respecto a sus predecesores. A pesar de la brevedad temporal con la que se desarrolla la acción de la fábula (una tarde, desde el mediodía hasta el anochecer), a Góngora parece atraerle de manera especial la escena de la seducción, y en ella se detiene. De hecho, mientras la unión amorosa propiamente dicha tiene lugar en solo tres estrofas (de la XL a la XLII, que subrayan lo inesperadamente breve de la resistencia de Galatea), el descubrimiento recíproco de los futuros amantes, las actitudes y movimientos previos a su himeneo, ocupan nada menos que diecisiete (XXIII-XXXIX). La presentación de la escena se demora en detalles gestuales y en la muy precisa descripción del desplazamiento de los personajes, todo ello acompañado de recursos retóricos, léxicos, sintácticos y métricos que marcan un tempo muy lento, traduciendo así la cautela sucesiva de ambos personajes pero sobre todo la de Galatea, sobresaltada por el ruido que provoca el cazador en el arroyo. Escribe Jammes que, despojada de todo dramatismo, la secuencia se cuenta solo a base de gestos y ademanes "que evocan irresistiblemente el ballet".

En otro lugar me he ocupado del reducido espacio en el que se desarrolla la escena (el riachuelo, unos mirtos y un laurel en su orilla) y también de los movimientos de la ninfa, que traté de precisar en virtud de las conexiones y paralelismos que entrelazan las estrofas ${ }^{7}$. Dedicaré estas páginas a

6 Robert Jammes, op. cit., p. 457.

7 Véase el análisis de la escena y su plasticidad a propósito del controvertido verso de la octava XXVIII en Isabel Román Gutiérrez, "Segur se hizo de sus azucenas o la ninfa en el arroyo (Polifemo, XXVIII, 220)”, BRAE, XCIV, 314 (julio-diciembre de 2016), pp. 221-261. Aceptando el reto propuesto por José María Micó, "Un verso de Góngora y las razones de la filología”, Criticón, 75 (1999), pp. 49-68 (también en De Góngora, Madrid, Biblioteca Nueva, 2001, pp. 157-190; y Para entender a Góngora, Barcelona, Acantilado, 2016, pp. 69-93), defiendo ahí la variante "segur" e interpreto el movimiento y la posición de la ninfa tras su brusco despertar: Galatea, sobresaltada, se mete en el arroyo, ofreciendo la imagen de sus blancas piernas quebradas por la línea del agua, que desde la perspectiva del narrador parecen unas azucenas cortadas como por un hacha, una "segur". Esta lectura se sostiene funda- 
matizar los de Acis, después de quedar subyugado por la visión de la ninfa desnuda y de preparar cuidadosamente sus ofrendas. Tras esta acción, la octava XXVII deja en suspenso, a la luz de la interpretación tradicionalmente propuesta para sus cuatro últimos versos (el viento Favonio sopla suavemente en torno al lecho de Galatea), la posición o los movimientos del muchacho (y, en consecuencia, como se verá, sus intenciones): si la semiestrofa alude a la brisa que agita el lecho de hierba de Galatea, que es quien pasa a ser el objeto de la narración a partir de la octava siguiente, lo último que sabemos del joven es que se refresca en el arroyo (la próxima vez que aparezca, en la XXXII, estará “fingiendo sueño"):

Caluroso, al arroyo da las manos,

y con ellas las ondas a su frente,

entre dos mirtos que, de espuma canos,

dos verdes garzas son de la corriente.

Vagas cortinas de volantes vanos

corrió Favonio lisonjeramente

a la (de viento cuando no sea) cama

de frescas sombras, de menuda grama.

Como dije, Pozuelo ha señalado con mucha precisión las marcas formales, las deixis espacio-temporales, los paralelismos y simetrías que funcionan como conectores discursivos y distribuyen los materiales de la inventio, y a su trabajo remito al lector para el conjunto de la fábula. Aunque me centraré en las estrofas dedicadas a Acis (XXIV-XXVII), y en particular en la XXVII, es inevitable, sin embargo, referirse a algunas de las anteriores

mentalmente en la implacable lógica gongorina y en las conexiones que el cordobés, con una precisión formidable, establece entre las estrofas, sin desechar el carácter visual y pictórico de la imagen. La cercanía entre los mirtos y el laurel remite a Virgilio: junto con el "bodegón" de las ofrendas de Acis, componen un escenario similar al que ofrece la Bucólica II (51-55), en la que Coridón quiere ofrecer a Alexis membrillos, castańas y ciruelas que colocará junto a mirtos y laureles: "y os pondré juntos, / oh laureles y mirtos, ya que juntos / unís tan bien vuestra fragancia suave" (Virgilio, Obras completas, trad. de Aurelio Espinosa, Madrid, Cátedra, 2003, pp. 106-107). 
y posteriores. Recordemos que en la primera mitad de la XXIII Galatea encuentra junto a un arroyo un laurel, a cuya sombra se tiende sobre la hierba, y enseguida, en la segunda semiestrofa, se queda dormida. La siguiente (XXIV) retoma la mención del mediodía y narra la aparición de Acis y su inmediata fascinación al contemplar a la nereida. La XXV continúa la descripción del joven y su enamoramiento y la XXVI detalla la ofrenda que deja al lado de Galatea. Se lava en el riachuelo en la primera mitad de la XXVII, mientras que los cuatro últimos versos se ocupan de describir una ligera brisa que vela suavemente, a modo de sutil cortina, el sueño de un personaje que descansa sobre un lecho de hierba.

A propósito de los conectores de las octavas IV, V y VI, que dan comienzo a la fábula describiendo al cíclope y su entorno tras la dedicatoria (y en particular al pues de la VI, que sigue a las deixis adverbiales y pronominales de las precedentes —donde, allí, este-), advierte Pozuelo la poderosa conciencia de unidad discursiva que se deriva del relato,

como si Góngora quisiese mostrarnos que las estrofas dedicadas a la descripción del locus de la cueva son desarrollos de un único argumento por partes, que van ligándose unas a otras por la propiedad conectiva de las deixis y del conector discursivo con que, a modo de conclusión, inicia la última de ellas ${ }^{8}$.

Y también hace notar las funciones de estos conectores en la octava que sigue a la que nos ocupa:

En la larga serie de estrofas que narran el encuentro amoroso de Acis y Galatea (22 estrofas nada menos) hay distintas alternancias; unas veces se describe a Acis, otras veces a la ninfa, en cambios de focalización constantes. Pues bien, estos cambios obligan al narrador a incluir alguna vez un conector discursivo, que sirve de embrague narrativo. Así ocurre al comienzo de la estrofa 28 [...]. Fíjese el lector en que el conector empleado por Góngora vuelve a ser doble: por un lado el conector "pues", que sirve de enlace o marca para el cambio de focalización y que actúa asimismo de instancia consecutivo-temporal que indica el cambio de acción, foco y con valor de "en el momento en que...". Justo ese valor consecutivo-temporal del conector, en el 
orden narrativo-argumentativo de la escena, es el que justifica y recoge la conjunción eminentemente narrativa "cuando", que inicia la nueva acción de Galatea?

Tras la irrefutable argumentación de Pozuelo, resulta cuando menos discutible que los cuatro últimos versos de la estrofa anterior, la XXVII, sigan interpretándose en relación con Galatea. Y es que, en general, se mantiene la visión de los comentaristas más cercanos a Góngora. Según Pellicer, "Haze cama de viento al sitio donde dormía Galatea, y dize que corrió las cortinas Favonio, que para despertalla sopló suavemente. [...] Si el sitio donde dormía Galatea no era cama de viento, era lecho de sombras por cortinas, y por pluma mullida la grama”. Tampoco sería el viento Favonio, por su suavidad (marcada por la aliteración alterna de labiales y nasales), el causante del despertar de Galatea, como aquí señala Pellicer. El motivo de la interrupción del sueño de la ninfa, a tenor de lo que explica la siguiente octava, no es otro que el ruido que Acis provoca en el agua, deliberadamente según el propio Pellicer, que más adelante se contradice: seńala a propósito de la estrofa XXXIV que “... Acis cuando la vio dormida, no trató de enfrenar el arroyo, antes lavándose y beviendo, hizo ruido para que despertasse" ${ }^{10}$ :

La ninfa, pues, la sonorosa plata

bullir sintió del arroyuelo apenas,

cuando, a los verdes márgenes ingrata,

segur se hizo de sus azucenas.

En su afán por refutar a Pellicer, Andrés Cuesta niega toda su argumentación y convierte a Favonio en el protagonista absoluto de los versos: "No haze aquí 'cama de viento' al sitio donde dormía Galatea, como pensó alguno. Antes lo contrario; usa el Poeta de una elegantísima metáfora para decir que se levantó un vientecico que soplava mansamente. I la cama no era de Galatea, sino de Favonio"11.

9 Ibidem, pp. 450-451.

10 José Pellicer, Lecciones solemnes a las obras de don Luis de Góngora, Madrid, Imprenta del Reino, 1630, cols. 192 y 234.

11 José María Micó, "Góngora en las guerras de sus comentaristas. Andrés Cuesta contra Pellicer”, El Crotalón. Anuario de Filología Española, 2 (1985), pp. 401-472 (p. 464). 
Salcedo Coronel mantiene, ampliada en algunos detalles, la interpretación de Pellicer:

Alude a la costumbre que ay de correr la cortina de la cama quando se ha de vestir alguna persona, o quieren que despierte, y dize que Favonio corrió lisonjeramente las cortinas a la cama en que dormía Galatea, que era de fresca sombra y menuda grama, ya que no de viento $^{12}$.

No advierte el comentarista la noción de ocultamiento que está en su primera explicación de la "costumbre" de correr la cortina, y que don Luis manejó certeramente en el envío de la canción "¿Qué de invidiosos montes levantados...!"13, en la que el desdeñado amante, a través de la propia canción, pide a su pensamiento que oculte la escena amorosa, que deje de contemplarla en su imaginación:

Canción, di al pensamiento

que corra la cortina

y vuelva al desdichado que camina.

Esta lectura, a mi modo de ver errónea, parece perpetuarse en la crítica moderna. Vilanova (que ignora la existencia de las "camas de viento" o de viaje), escribe:

El soplo del viento Favonio corrió lisonjeramente cortinas imprecisas e impalpables, vagas cortinas de volantes irreales y vanos, como si su leve soplo corriese suavemente unas cortinas invisibles en torno al lugar en donde descansaba Galatea dormida, cama de frescas sombras, de menuda grama, que parecía la misma cama del viento ${ }^{14}$.

12 García de Salcedo Coronel, El "Polifemo" de don Luis de Góngora comentado, Madrid, Imprenta Real, 1636, fol. 57r.

13 Espléndido poema al que Jesús Ponce ha dedicado varios trabajos, y entre ellos una monografía: Jesús Ponce Cárdenas, "Evaporar contempla un fuego helado": género, enunciación lírica y erotismo en una canción gongorina, Málaga, Universidad, 2006.

14 Antonio Vilanova, Las fuentes y los temas del "Polifemo" de Góngora, Barcelona, PPU, 1992 [1957], II, p. 119. 
Y tampoco Alfonso Reyes pone objeciones a la lección tradicional, aunque incluye una precisión a propósito de la cama:

Favonio, el céfiro, la brisa, con suave soplo, remeció entonces las vagas frondas - remedo de los volantes que flotan al aire en las tocas de las mujeres- como se corren las cortinas de una cama. La cama en que Galatea reposa, si no es una "cama de viento" como las que hoy se usan, lo es de fresca sombra y menuda grama ${ }^{15}$.

Para Dámaso Alonso, "un suave céfiro que mansamente soplaba, corrió las vagas cortinas de vanos volantes de sus ondas, sobre el sitio donde Galatea dormía, lecho que (si no le queremos llamar cama de viento), era una cama de grama menuda y frescas sombras"; y más adelante insiste: "en la segunda parte de la estrofa un ligerísimo céfiro se mueve y va a dar sobre el lecho de hierba sobre el que duerme Galatea"

Los versos, sin ser considerados "reacios" (expresión que adjudicó Alfonso Reyes a la estrofa $\mathrm{XI}^{17}$ ), no han encontrado todavía entre los más recientes exégetas una explicación satisfactoria, tal vez por la inercia crítica que los sigue relacionando con Galatea; no dejan, sin embargo, de ser objeto de reflexión. Así, por ejemplo, Rubén Soto Rivera (que relaciona varios pasajes de la fábula gongorina con las Imágenes de Filóstrato el Viejo) parte de los interrogantes de Dámaso Alonso al respecto, desecha la interpretación de Vilanova por insuficiente y propone una nueva relación: las "cortinas" de Favonio, como la "cama de viento", similar a una hamaca, evocarían la tela de color púrpura con la que Galatea aparece representada en la pintura, que sirve de vela a su carro marino y que Filóstrato describe ${ }^{18}$. Esta lectura sigue remitiendo a Gala-

15 Alfonso Reyes, "I. Fábula de Acis y Galatea", en El "Polifemo" sin lágrimas. La "Fábula de Polifemo y Galatea". Libre interpretación del texto de Góngora, Obra completa, México, FCE, 1991 [1961], XXV, pp. 241-278 (p. 277).

16 Dámaso Alonso, Góngora y el "Polifemo", Madrid, Gredos, 1994 [1960], pp. 515 y 517.

17 Alfonso Reyes, "II. La estrofa reacia del Polifemo", en El "Polifemo" sin lágrimas, pp. 279-293.

18 Rubén Soto Ribera, "El Cíclope de Filóstrato el Viejo en el Polifemo de Góngora”, Confluencia. Revista Hispánica de Cultura y Literatura, 16, 2 (2001), pp. 99-106 (pp. 100-101). 
tea sin que pueda percibirse, además, la idoneidad de la imagen en este pasaje concreto.

Tampoco Jesús Ponce ofrece una interpretación distinta, e incluso da por concluida la función de ocultamiento que cabe atribuir a las cortinas, pues entiende que lo que hace la brisa es descubrir el lecho de Galatea: "la brisa templada del oeste abrió las aéreas cortinas de volantes que velaban el lecho de hierba donde yacía la nereida" ${ }^{19}$. Esta lección resultaría redundante e incluso contradictoria, dado que Acis había descubierto a la nereida inmediatamente, tras su llegada, en la estrofa XXIV: la mira ("de ambas luces bellas / dulce occidente viendo al sueño blando"), la contempla a su sabor ("su boca dio, y sus ojos cuanto pudo, / al sonoro cristal, al cristal mudo" ${ }^{20}$; no se dice en ningún momento, por tanto, que la ninfa estuviese escondida u oculta.

Ni siquiera puede hablarse, como parece sugerir Gerhard Poppenberg al entender que la escena en la que se describen los mirtos como garzas funciona como "preludio de la siguiente: el coito de Acis y Galatea", de que durante esa secuencia oculta — la de la unión amorosa- "el viento, que circula entre los arbustos, corre el telón" ${ }^{21}$ : la ninfa aún no se ha sobresaltado ni ha descubierto a Acis, proceso en el que Góngora se detiene con delectación. No procede, pues, todavía el ocultamiento.

Es José María Micó el único que deja en el aire la posibilidad de que los versos se refieran al espacio que ocupa cualquiera de los dos personajes; sin especificar, adscribe la semiestrofa a la ambientación general:

19 Jesús Ponce Cárdenas (ed.), Fábula de Polifemo y Galatea, op. cit., p. 265. Más por extenso, considera en El tapiz narrativo del "Polifemo", pp. 87-88, que la función de las cortinas es aquí la contraria a la de la citada canción: si en esta ocultaban la escena, en la Fábula desvelan el cuerpo de Galatea: "Al cotejar ambos pasajes, se puede apreciar que el movimiento en los dos poemas resulta exactamente el inverso. En los versos de la rara canción petrarquista el osado pensamiento debe cerrar las cortinillas del tálamo para interrumpir la envidiosa vista del exclusus amator, intruso al que ya le ha sido concedido observar más de lo que debiera. Por el contrario, en las octavas del relato mítico, la brisa templada del oeste (el dios Céfiro, bajo la advocación menos usual de 'Favonio') descubre ante el obnubilado cazador el invitador paraje donde duerme Galatea: el numen abre los cortinajes de la sencilla 'cama de viento' y ofrece la figura durmiente de la ninfa a la deleitosa contemplación de Acis".

20 La redonda es mía.

21 Gerhard Poppenberg, op. cit., p. 234. 
En todo caso, creo que el airecillo, la sombra y el colchón de grama [...], más que definir en concreto el lugar en que descansan Galatea (vv. 177-180) o Acis (vv. 254-256), configuran y anticipan el entorno más propicio para el encuentro amoroso que vendrá (XXXIX-XL), y ello con los recursos poéticos más adecuados para plasmar la musicalidad y la armonía propias de la ocasión ${ }^{22}$.

La ambigüedad no es precisamente un rasgo de la poesía gongorina. Como indica Carreira, en Góngora "hay indicadores de discurso que muestran su voluntad de ser preciso en la dicción poética, de construir un equilibrio entre la indeseada ambigüedad y la necesaria polisemia" 23 .

De aceptar la lectura de los versos en relación con Galatea, se resentiría la estructura de la escena, que comienza cuando la ninfa detiene su huida y se entrega al sueńo en la estrofa XXIII. Mientras duerme, aparece Acis, a quien se dedican las cuatro octavas siguientes. $\mathrm{Y}$ es preciso recordar que, tras ellas, el principio de la XXVIII ("La ninfa, pues, la sonorosa plata...”), contiene un conector, la conjunción "pues”, destacada entre comas y colocada inmediatamente tras la mención de la ninfa, que, desde la estrofa en que la dejamos durmiendo tras concluir su carrera, solo había sido aludida como "cristal mudo o ídolo dormido", siempre, por lo tanto, desde la perspectiva de Acis. Como hace notar Pozuelo, la focalización cambia a menudo, y ahora Galatea es descrita a través de la apasionada mirada del joven. Desde la octava XXIV, cuando irrumpe el cazador en el escenario, la ninfa no aparece más que como objeto, sucesivamente, de su mirada (en la misma XXIV), de su enamoramiento (XXV) y de sus ofrendas (XXVI: "se lo puso al lado"). El narrador centra su atención en el joven (que a su vez está pendiente de la nereida), y solo vuelve a ocuparse de Galatea en la XXVIII, cuando ofrece, además, su propia perspectiva (cambiando, en efecto, la focalización) al transmitir la violencia visual que supone la contemplación de la imagen de la bellísima ninfa cortada

22 José María Micó, El "Polifemo" de Luis de Góngora. Ensayo de crítica e historia literaria, Barcelona, Península, 2001, p. 52.

23 Antonio Carreira, "Defecto y exceso en la interpretación de Góngora”, en sus Gongoremas, Barcelona, Península, 1998, pp. 47-94 (p. 50). 
por la línea del agua del riachuelo al que ha saltado ${ }^{24}$. Y, además, en el verso tercero la conjunción "cuando" retoma la narración de las acciones de la ninfa, del mismo modo que señalaba, si bien en este caso con valor adverbial de tiempo, en la octava XXIV la aparición de Acis ("latiendo el can del cielo estaba [...] cuando / llegó Acis”). Las estrofas XXIV, XXV, XXVI y XXVII suponen entonces un paréntesis que, mientras la ninfa duerme, presenta la llegada del muchacho, su descripción, su enamoramiento y su actuación.

La remisión a Galatea en los versos que describen la brisa en torno al lecho se percibe también como incoherente si tenemos en cuenta el perfecto paralelismo que se establece entre las estrofas XXIII y XXVIII, referida la primera de ellas a Galatea y la última a Acis: en la primera mitad, ambos intentan mitigar el calor, Galatea buscando la sombra y el frescor del arroyo y la hierba para protegerse del "sol ardiente" y Acis, "caluroso", lavándose la cara en el mismo riachuelo; si Galatea se entrega al sueño en la segunda mitad, cabe pensar que la mención de la "cama / de frescas sombras, de menuda grama" se refiera a que Acis busca también acomodo sobre la hierba para fingir que duerme: otro lecho de verdura, frescor y sombras, obligadamente cercano.

El paralelismo podría acentuarse de aceptar la interpretación que para los primeros y complejos versos de la estrofa propone Vilanova ${ }^{25}$. A propósito de los jazmines con los que la nieve de los miembros de la ninfa cubre la hierba (objeto de discusión también desde los primeros comentaristas), Vilanova no solo acepta la posibilidad de que la blancura de Galatea se refleje en el riachuelo (posibilidad discutida, con razón, por Carreira, pues se ve dificultada por el hecho de que en las estrofas XXVII, XXVIII y XXXIV el arroyo bulle y forma "dulce estruendo" y "espumas"26), sino que sugiere que sumerge en el agua, para refrescarse, parte de su anatomía. Encuentra, sin embargo, algunos obstáculos para esta interpretación: el

24 Véase Isabel Román Gutiérrez, op. cit.

25 "Encierra este pasaje uno de los más indescifrables misterios de la obra gongorina. Pese a la mágica potencia evocadora de estos versos, cuya belleza refinada y sensual parece evocar la blanquísima desnudez de la ninfa dormida sobre la hierba verde, junto a una fuente de aguas límpidas, es absolutamente imposible determinar su verdadero sentido", escribe Antonio Vilanova, op. cit., p. 34.

26 Antonio Carreira, op. cit., p. 181. 
sentido que le da a la "fuente", término que para Vilanova "complica el sentido del pasaje", y el inmediato tránsito de la ninfa al sueño:

Es evidente, sin embargo, que la interpretación más verosímil del texto gongorino es esta: "la ninfa, recostada en el margen de una fuente, refleja en sus aguas tantos jazmines de sus miembros blanquísimos como hierba esconde la nieve de su cuerpo recostado sobre el césped". Lo cual no puede interpretarse de otro modo que el siguiente: "la ninfa, recostada en el margen de una fuente, refleja su cuerpo blanquísimo en el agua”. Parece, sin embargo, que la expresión dar sus jazmines a una fuente sugiere más bien la idea de sumergir sus miembros en el agua de la fuente, es decir, bañarse en sus aguas, pero en primer lugar existe la imposibilidad de bañarse en una fuente, y en segundo lugar, la inmediata transición al sueño que cierra los ojos de la ninfa indica bien a las claras que estaba recostada sobre la hierba y que daba a la fuente su imagen, no sus miembros ${ }^{27}$.

Dámaso Alonso explica, sin embargo, que la 'fuente' no es solo el manantial, sino el agua que de él corre e incluso sus orillas ${ }^{28}$ : el primer inconveniente queda, pues, zanjado, habida cuenta, además, de que en el mismo arroyo se refresca Acis. Nada impide pensar que, como después hará el joven, Galatea refresque sus manos o sus brazos (no olvidemos que se mencionan "sus miembros") y después su rostro. Con esta interpretación conviene González Ollé, aunque se enreda en qué parte del cuerpo de la nereida queda en la hierba y qué parte en el agua, perdiéndose luego en elucubraciones casi matemáticas:

Todo el cuerpo de Galatea es nieve, al esconder la yerba; todo él es, simultáneamente, jazmines al reflejarse en el agua. Nada hay que objetar; desde el punto de vista sintáctico resulta perfectamente correcto. Pero con idéntica validez pueden aludir a partes iguales de la misma totalidad: parte del cuerpo de Galatea es nieve al esconder la yerba, parte de él es, simultáneamente, jazmines al abatirse sobre el agua. [...] Esta es, pues, mi interpretación: Galatea, abatida sobre la

27 Antonio Vilanova, op. cit., p. 35.

28 Dámaso Alonso, op. cit., p. 520 . He comentado también este asunto, a la luz de los comentaristas gongorinos, en "Segur se hizo de sus azucenas...", op. cit. 
fuente, sumerge en ella la cabeza para beber o (y) refrescarla. Nada más lógico, nada más natural que este refrigerio, antes de entregarse al descanso, en el ardoroso mediodía, tras la fatiga de la fuga ${ }^{29}$.

No diré yo la cabeza (que, a no ser que la ninfa hubiese encanecido prematura e instantáneamente, sería difícil equiparar a la nieve), pero sí es aceptable que, como Acis, Galatea dé "al arroyo las manos, / y con ellas las ondas a su frente”. El paralelismo entre las estrofas XXIII (dedicada a Galatea) y XXVII (dedicada a Acis) sería perfecto: ambos se refrescan en el arroyo (con similar construcción sintáctica: "da a una fuente la nieve de sus miembros", en el primer caso; "da al arroyo las manos", en el segundo) y de inmediato se entregan al sueño (fingido, en el caso de Acis), hecho este que, como se ve en las últimas líneas de la argumentación de González Ollé, no resulta incoherente, a pesar de los reparos de Vilanova. No deja de decirse, además, que la ninfa se tiende: da al agua los jazmines de sus miembros, que como nieve ocultan después la hierba. E incluso podría pensarse en una construcción ceugmática con respecto a la forma verbal.

El paralelismo entre las estrofas, pues, coloca a Galatea y a Acis en camas que se caracterizan del mismo modo: sombreadas y frescas. Solo cuando se intuye que el lugar elegido por Acis para su fingido reposo se convertirá en escenario de la batalla amorosa recibirá otros calificativos, más acordes con el acontecimiento que allí se desarrollará.

Si los cuatro últimos versos de la estrofa XXVII se refiriesen a Galatea, resultarían redundantes en la medida en que no ańaden significación nueva con respecto a la frescura del lecho de hierba sombreado de la ninfa; tampoco se entiende como decisiva en ningún aspecto la acción del viento Favonio. Referidos a Acis, en cambio, permiten que cobren sentido las referencias posteriores a su aparente sueńo: cuando la nereida lo descubre, lo encuentra "en la umbría / cama de campo y campo de batalla / fingiendo sueńo". No es casualidad que al hallazgo de la ninfa le acompañe una nueva observación sobre la cama, que sigue siendo sombreada y de hierba (como antes la de Galatea, que cubre de jazmines la hierba sobre la que se

29 Fernando González Ollé, "Tantos jazmines cuanta yerba esconde / la nieve de sus miembros da a una fuente", Revista de Literatura, XVI, 31 (1959), pp. 134-146 (p. 138). 
tiende a la sombra del laurel, o la de Acis, "de frescas sombras, de menuda grama”), pero ahora "de campo" (amplia y espaciosa), anunciándose ya, además, como escenario de la batalla amorosa. Los paralelismos, pues, funcionan también como instrumentos distributivos de la narración. La precisión gongorina es, una vez más, extraordinaria. El mismo procedimiento, también con recurrencias léxicas y significativas, permite ajustar la interpretación de la primera mitad de la estrofa XXXI ("Entre las ramas del que más se lava / en el arroyo mirto levantado, / carcaj de cristal hizo, si no aljaba / su blanco pecho de un arpón dorado"), precisando que quien está entre las ramas del mirto es Galatea, y no Cupido, a la luz de la lectura de la segunda mitad de la XXXIV: "A pesar luego de las ramas, viendo / colorido el bosquejo que ya había / en su imaginación Cupido hecho / con el pincel que le clavó su pecho" ${ }^{30}$.

La alusión a un lecho de hierba sutilmente oculto (sutileza marcada por las múltiples aliteraciones de labiales, nasales, líquidas, sibilantes, dentales: vagas, cortinas, volantes, vanos, Favonio, lisonjeramente, viento), solo velado por el aire, ha de relacionarse, pues, con Acis, que se apresura a echarse sobre la hierba; el escenario, como dije, es muy reducido, y el muchacho no se aleja: el "apenas" del segundo verso de la siguiente estrofa proporciona el mínimo lapso temporal para que el cazador se "oculte" antes de que Galatea, alarmada por el ruido del agua, le descubra. Al sugerir el lecho de hierba, delicadamente rodeado por la brisa, Góngora completa, sin describirlos, los movimientos y la acción de Acis, pero también su propósito. Si prescindimos de la intervención de Favonio en favor del joven, nada sabríamos tampoco de sus gestos, sus actitudes, tan morosamente detallados, por el contrario, con respecto a Galatea (morosidad que permitía a Robert Jammes evocar un ballet). Se nos habría escamoteado el momento en que el muchacho toma la decisión de ocultarse y engañar a Galatea. Quedaría incompleto el relato, toda vez que solo volveremos a encontrar a Acis, a través de la mirada de la ninfa, en la

30 Isabel Román Gutiérrez, op. cit. José María Pozuelo Yvancos, op. cit., pp. 451-452, señala, entre otros, un caso similar a este entre las estrofas XIII y XLVI, que describen la hermosura de Galatea en relación con las aves de Venus y Juno desde la perspectiva del narrador, en la primera, y desde la de Polifemo en la segunda: las recurrencias funcionan a modo de isotopía, de vínculo semántico "que cohesiona fuertemente la narración y el sentido de este poema”. 
octava XXXII, cuando la omnisciencia del narrador declara al lector un dato que Galatea ignora: el joven está “fingiendo sueño”. Pero, como dije, Góngora evita narrar esa acción, determinante en la argucia del cazador. Es uno más de los ejemplos de la que Aurora Egido determinó "poética del silencio", tan usada por Góngora:

La palabra eludida sabemos que fue fundamental en Góngora. Su pretensión — bajo dictado de Ovidio — no fue otra que la de evocar en el lector un mundo de imágenes, vale decir, palabras, que no necesitaban ser nombradas para existir en el poema. Se trata de un silencio creador suscitante de cuanto la lectura va a hacer surgir más allá de lo explícito. [...] La narración suspendida, la imagen inacabada, la elusión del lugar común, el desdén por la evidencia: todo son marcas que la retórica ofrece a la evocación del lector y que piden su connivencia. Este agradecerá comprobar hasta qué punto el poema sortea adjetivos, evita redundancias, apela a lecturas sugeridas sin nombrarlas, dice callando ${ }^{31}$.

El fingido sueño de Acis se equipara en la fábula misma con un "retórico silencio, mentido" en tanto que falso: la ninfa, que "haciéndolo dormido" se muestra "urbana al sueño" (es decir, lo respeta), es, sin embargo, "bárbara" acerca de su fingimiento, del que nada sabe (estrofa XXXIII) y, por lo tanto, presa fácil del engańo. El sueño es, ahora, silencio; un silencio "retórico" por más seńas, artificioso y, como anotara Díaz de Rivas, encaminado a poner en funcionamiento el movere: "porque con él persuadía, y la movía a amarlo con la belleça de su rostro, junto con la cortesía de los presentes, y de no averle inquietado el sueño" 32 .

También el narrador guarda un silencio artificioso en la estrofa XXVIII, tanto para potenciar la estratagema del enamorado cazador como para estimular la colaboración del lector. No se trata en este caso propiamente

31 Aurora Egido, "La poética del silencio", en Fronteras de la poesía en el Barroco, Barcelona, Crítica, 1990, pp. 56-84 (p. 82).

32 Pedro Díaz de Rivas, "Anotaciones al Poliphemo", ed. James Robert Feynn, Pedro Díaz de Rivas' Comentary on Góngora's "Polifemo", Rocksprings, Texas, 1951 (disponible en https://ttu-ir.tdl.org/ttu-ir/handle/2346/11885; consultado por última vez el 8 de junio de 2016). 
de una elipsis (que no en vano Egido relaciona con la técnica narrativa ${ }^{33}$ ), sino de la sustitución de una mención directa o explícita por una construcción sugerente a modo de metonimia: la descripción del lecho evita contar que el muchacho se dispone a dormir; si la cama de hierba está delicadamente velada por cortinas de aire, el sueño será aparente, simulado y engañoso.

$\mathrm{Y}$ es que Góngora no solo pone en funcionamiento la "retórica del silencio" con ocasión de guardar la "honesta oscuridad" de la que hablaba Salcedo Coronel $^{34}$, analizada por Ponce en relación con el lapso de tiempo transcurrido desde la unión de los amantes en plena canícula (el decisivo "ya" ${ }^{35}$ del último verso de la estrofa XLII, oculto tras la cortina de flores) hasta el comienzo del canto de Polifemo al anochecer, que escuchan aun atados con "los nudos más suaves" (estrofa LX) ${ }^{36}$.

En diversos lugares de la Fábula puede percibirse que Góngora se guarda de ser demasiado explícito, porque cuenta con la competencia del lector, verdadero protagonista, como apunta Jaime Siles, de su lengua y de su obra, y a quien reta continuamente. Góngora "obliga a su lector a

33 Aurora Egido, op. cit., p. 82.

34 A propósito de la canción “¿Qué de invidiosos montes levantados...!”, comenta: "Descrive con elegancia los lícitos gustos que permite el conyugal lecho, con tan honesta oscuridad, que no llega a ofenderse la castidad más severa". Véase García de Salcedo Coronel, Segunda Parte del Segundo Tomo de las Obras de don Luis de Góngora comentadas, Madrid, Diego Díaz de la Carrera, 1648, p. 100.

35 Con ser suficientemente explícita, no es esa la única función de la partícula: el monosílabo, que irrumpe gracias a su fuerza tónica de manera contundente y brusca en la mitad del verso, advierte de la inmediata separación de los amantes (del mismo modo que separa sus nombres), apoyado este significado por la connotación dolorosa que la disposición léxica y versal de la lluvia de flores aporta: Pafo y sus negras violas, presagio de muerte, ocupan el primer hemistiquio, en el que también se coloca Acis; Gnido y sus blancos alhelíes caen de manera gráfica a lo largo del segundo sobre Galatea. Góngora conoce y utiliza el motivo tradicional del epitalamio, pero enriquece su significación.

36 Jesús Ponce Cárdenas, "Introducción” a Luis de Góngora, Fábula de Polifemo y Galatea, pp. 50-61. Más detenidamente aborda el mismo Ponce el asunto en El tapiz narrativo del "Polifemo", p. 32. Y del mismo procedimiento se ocupa a propósito de la canción "Qué de invidiosos montes levantados" en este mismo libro ("Las horas no relatadas: función y alcance del silencio en el poema gongorino", pp. 69-154) y en "Evaporar contempla un fuego helado". 
traducirlo: esto es, a analizar la sintaxis de sus frases y a navegar por la mitología en metonimias que forma el sistema cifrado de sus alusiones, elusiones, ilusiones y ocultas y complicadas referencias" ${ }^{37}$. Góngora evita en muchas ocasiones indicar el movimiento mediante una forma verbal directa. Es el caso, por ejemplo, del controvertido verso de la "segur", cuyas dificultades interpretativas derivan en buena medida de que no se expresa el movimiento de la ninfa (el salto al agua), sino las consecuencias que resultan de esa acción: la ingratitud hacia los márgenes del arroyo, la imagen de sus piernas visualmente cercenadas. Tampoco en las tres estrofas que conforman el núcleo de la unión amorosa se explicita el movimiento de los personajes. La primera parte de la octava anterior, la XXXIX, nos presenta a una Galatea menos esquiva e incluso complaciente, dispuesta a conceder "treguas al reposo". En la segunda mitad, la mirada del narrador se dirige hacia el hueco de una peña que ofrece intimidad (unas hiedras trepan por troncos y piedras y se convierten en una celosía que puede ocultar a los amantes) y frescura ("fresco sitial") gracias a la vegetación (mirtos, que pueden ser los mismos de las estrofas anteriores) que les resguarde del sol del mediodía ("dosel umbroso"). La única referencia al desplazamiento de los jóvenes la encontramos ya en el inicio de la segunda mitad de la octava siguiente: el participio reclinados, al que llegamos tras un larguísimo hipérbaton (que comenzaba con la primera parte de la cláusula absoluta, "sobre una alfombra") trenzado de incisos que, como demostró Senabre ${ }^{38}$, van indicando el acercamiento al suelo (es decir, el movimiento de tenderse) mediante la visión de la delicada textura de la alfombra y sus deliciosos colores (como elaborada de antemano por la Primavera para cobijar el cumplimiento del previo mandato de Cupido): solo al aproximarse a ella es posible percibir el primor de su tejido. Si antes la mirada del narrador se dirigía hacia arriba, en esta estrofa traduce la de los amantes, que se acercan a la alfombra de hierba. El lugar queda ahora descrito por completo, pero no la posición de los

37 Jaime Siles, "Estrategias de lector y experiencias y posibilidades de lectura: Góngora siempre recomenzado", en Góngora hoy I-II-III, ed. Joaquín Roses, Córdoba, Diputación Provincial, 2002, pp. 347-367 (pp. 347 y 349).

38 Ricardo Senabre, "Sintaxis y métrica", en Capitulos de historia de la lengua literaria, Cáceres, Universidad de Extremadura, 1998, pp. 49-59 (pp. 50-51). 
amantes, que tampoco se explicita del todo. Mediante procedimientos que no son estrictamente léxicos, Góngora expresa que la timidez de los jóvenes impide todavía su unión. Están tumbados, pero ni siquiera se miran. La focalización del narrador en sus miradas indica que ambos están tendidos boca arriba, porque lo que ven, y lo que el narrador describe, es el "dosel umbroso" de la octava anterior: unas palomas que "se calan" (en persecución amorosa: "una y otra”, esto es, una tras la otra) al mirto más lozano. Los detalles, pues, son mucho más complejos de lo que el simple "reclinados" permitiría deducir. La lucha amorosa comienza en la siguiente octava, en la que sus nombres, como contendientes que son, aparecen separados en cada una de las semiestrofas, para unirse, cuando triunfa el amor pero se anuncia la muerte, en el verso final de la octava siguiente.

El procedimiento de la elipsis sirve, pues, también en la estrofa que nos ocupa, para insinuar una información no explícita, y tiene muy presente al lector: el personaje se oculta para Galatea y para el destinatario activo que Góngora reclama, que ha de captar la sugerencia gongorina, entender la metonimia de la "cama" e intuir que el muchacho se tiende en la hierba tras las sutiles y poco efectivas cortinas del viento. También a estos versos de la octava XVIII, que aún no rozan lo "deshonesto", puede aplicárseles el comentario de Ponce:

Salvando las pertinentes distancias, la estratagema urdida por Acis se asemeja en cierto modo a la táctica narrativa empleada por el autor. El Symaethius heros vence el pudor de Galatea instándola a romper las distancias, a acercarse a él; Acis la convence con el retórico silencio de un sueño fingido y con la elocuente belleza de su cuerpo y de su rostro. Por su parte, el genial poeta presenta ante los asombrados ojos de sus lectores el amplexo de una pareja de enamorados mediante quiebros alusivos, rodeándolo de un silencio elocuente, cubriéndolo con el velo de una omisión que invita a los receptores del poema a suplir tal ausencia con las audacias de su fantasía ${ }^{39}$.

No es posible explicar de otro modo la ausencia de Acis. El "apenas" de la estrofa siguiente indica que, nada más oír el ruido del agua, Galatea

39 Jesús Ponce Cárdenas, "Introducción” a Luis de Góngora, Fábula de Polifemo y Galatea, p. 60. 
se oculta en el arroyo, y desde allí, dando solo un paso y asomándose por encima de un mirto, si bien muy despaciosamente, descubre al muchacho. Teniendo en cuenta, además, como dije, lo muy reducido del espacio en el que se mueven los personajes, prescindir de la relación de la cama y el viento Favonio con Acis equivaldría a no dar razón de su movimiento ni su actitud. La maniobra de ocultamiento de Acis se sugiere en esta estrofa, y se confirma en la XXXII, cuando la ninfa lo encuentra fingiendo sueño.

Si la suavidad de la brisa se desprende de la aliteración y de los adjetivos ("vagas", "vanos"), conviene no olvidar que lo que despliega Favonio son "cortinas de volantes", cuya función aquí no es la de provocar un ocultamiento físico y real, pues son de aire y, por lo tanto, inconsistentes. Aun así, el quiasmo "vagas cortinas de volantes vanos" sugiere el movimiento de unas cortinas que se corren y que, por lo tanto, impiden la visión (recordemos que ya Salcedo aludía a "la costumbre que ay de correr la cortina de la cama quando se ha de vestir alguna persona”). Creo que la sutileza gongorina consiste en sugerir mediante las aéreas cortinas, finas cómplices etéreas del muchacho — una complicidad subrayada por el adverbio "lisonjeramente" ${ }^{4}$ _, el ocultamiento de Acis desde un punto de vista psicológico: engañará a Galatea, pero no escondiéndose (porque solo el temor y la cautela de la ninfa demorarán su descubrimiento), sino haciéndose el dormido. Vagas y vanos son, de esta manera, adjetivos que no solo remiten a la delicadeza de la brisa, sino también al aparente sueńo del joven, tan inconsistente y ligero como el propio viento, convertido, como apunté, en cómplice de su estrategia amorosa: la suavidad del viento es equivalente a la cortesía de Acis; la "lisonja” que es capaz de desplegar Favonio, con el matiz semántico de engaño, remite a la astucia

40 Según Plinio, el viento Favonio empieza a soplar en febrero. Es anuncio de la primavera, relacionado etimológicamente con faveo ('favorecer', 'mirar con benevolencia') y "se aceptaba que favorecía la fertilidad" (Ana María Moure Casas, coord., Plinio el Viejo, Historia natural. Libros XII-XVI, Madrid, Gredos, 2010, libro XV, p. 269 y nota 3). "Lisonjeramente" remite a la cortesía, a la fineza y la suavidad, pero no pierde el matiz de engaño. Lisonja, según el Diccionario de Autoridades es "la nimia complacencia y afectada fineza que se tiene, en alabar y ponderar las prendas, obras o palabras de otro. Sale del italiano Lusinga, que significa Adulación". Y cita de las Partidas: "Porque tal alabanza como esta, es lisonja, que quiere tanto decir como loor engañoso" (la cursiva es mía). 
que mostrará el cazador.

Las cortinas sugieren, pues, el ocultamiento de Acis, pero es un ocultamiento "vago" y "vano", es decir, simulado y poco efectivo, como hecho de aire. La cortina de viento es más psicológica que real. Acis no queda oculto a la vista, físicamente, sino solo de modo imaginario, al cerrar él mismo los ojos en su actitud fingida, como en la canción citada más arriba la escena íntima queda metafóricamente velada tras una cortina imaginaria. Por eso se alude también, en un procedimiento similar a la lítote, a la cama "de viento": se menciona, aunque se niega, pero el término queda en el texto y con él su significado. Mazzocchi ha señalado en el pasaje la ironía gongorina (como en otros lugares de la Fábula) al insertar un elemento que remite a la realidad cotidiana ${ }^{41}$. Pero la ironía va más allá: hay que tener en cuenta la dilogía de la expresión, que Góngora maneja pero que deshace al desechar la significación que remite a la "cama de viento" real (improcedente en el contexto de la Sicilia bucólica, y que requeriría un tiempo del que Acis no dispone, dada la rapidez de la secuencia) para quedarse, en efecto, con una imaginaria cama "de viento", de aire, intangible e inexistente: por más que se trate de un lecho de hierba, no servirá para acoger el sueño del muchacho, que solo lo finge. Esto implica otro matiz irónico: la intervención del narrador, similar a las de otros pasajes de la fábula ("que no debiera", a propósito de la construcción de la flauta de Polifemo, en la estrofa XII), que en un guiño cómplice avisa al lector de la futilidad de la cama en el inciso del séptimo verso: a tenor del matiz condicional de la expresión, "de viento cuando no sea" equivale a "si es que no es de viento" (y también hay en el poema otras construcciones similares: "húmidas centellas, / si no ardientes aljófares, sudando", en la octava XXIV): tampoco es, pues, en realidad, una cama, pues no cumple esa función; a pesar de ser de hierba, es una cama fingida, y por lo tanto, en realidad, "de viento".

La interpretación de Favonio en relación con Acis elimina la imprecisión que se produce al asociar el lecho oreado por el viento con Galatea. El lector puede ahora deducir lo que hace el muchacho en tanto que

41 Giuseppe Mazzocchi, op. cit., p. 138. La “cama de viento", o cama de viaje, se improvisaba con un lienzo y unos postes. Véase Israel Lasmarías Ponz, "Vestido para viajar, 1600-1650", Revista de Historia Jerónimo Zurita, 80-81 (2005-2006), pp. 203-226 (p. 207). 
Galatea despierta y busca al causante del ruido. Pero, y esto es más importante, la anterior falta de indicaciones sobre el garzón (a quien habríamos dejado refrescándose en el arroyo, y Galatea debería haberlo encontrado enseguida) impediría percibir su estrategia de seducción. Siendo, como es, un cazador, el comportamiento de Acis con respecto a la ninfa nos remite no solo a la batalla de amor, cuyo triunfo celebra anticipadamente Cupido en la estrofa XXX colgando los despojos de la lucha (el desdén y la esquivez, hasta allí, de Galatea) del árbol de Venus, sino también a la "caza de amor" ${ }^{42}$. Pozuelo explica muy bien la victoria de Acis en la batalla amorosa a la luz de la estrofa XXXVII, siendo su fingido sueño el Paladión con que derrota a la ninfa: "La batalla la gana Amor, ¿cómo?, con los paladiones que introduce Acis en la muralla. Paladión era el caballo de Troya. Es un caballo fingido, una artimaña falsa, engañosa, como lo es el fingido y mentido sueño de Acis" ${ }^{33}$. La misma imagen puede servir para la caza, a la que Poppenberg ha dedicado, en relación con la metáfora bélica, unas esclarecedoras páginas ${ }^{44}$. También Rafael Bonilla Cerezo, en un detenido y muy bien documentado estudio, ha rastreado el sustrato cinegético, que modula la literatura pastoril, en las composiciones gongorinas previas a los "poemas mayores", lo que le permite concluir que la "montería pasional" de Acis "se inició veinte años antes de que el mismo racionero la escribiera", posibilitando así que estos puedan entenderse "en íntima trabazón con los sonetos, romances y letrillas" ${ }^{35}$.

42 El tema se rastrea desde la literatura medieval (El Conde Lucanor, la Celestina...) hasta Gil Vicente o San Juan de la Cruz. Dámaso Alonso, "La caza de amor es de altanería”, De los siglos oscuros al de Oro, Madrid, Gredos, 1958, pp. 254-275, se ocupó de espigar los antecedentes populares del tema en la poesía de San Juan. Para Domingo Ynduráin (ed.), San Juan de la Cruz, Poesía, Madrid, Cátedra, 1983, p. 221, su manifestación más temprana puede localizarse en las Metamorfosis. A este respecto escribe Irving Singer, La naturaleza del amor, I. De Platón a Lutero, Madrid, Siglo XXI, 1999, p. 154: "Ovidio ve el combate como el tema que domina en el amor: Cupido hiere el corazón con dardos ardientes, las mujeres son descritas como pájaros a los que hay que tender trampas, caza a la que hay que perseguir, botín para llevarse en un rapto general de Sabinas".

43 José María Pozuelo Yvancos, op. cit., p. 458.

44 Gerhard Poppenberg, op. cit., pp. 238-242.

45 Rafael Bonilla Cerezo, "Sus rubias trenzas, mi cansado acento: ciervas, cazadoras y corcillas en la poesía de Góngora", en Góngora hoy IX. "Ángel fieramente humano". Góngora y la mujer, ed. Joaquín Roses, Córdoba, Diputación Provincial, 2007, pp. 
Y, sin embargo, la interpretación de la escena de la seducción amorosa, entendida como "caza de amor", queda incompleta sin la lectura de los cuatro últimos versos de la octava XXVII en relación con Acis. El muchacho se conduce con Galatea como un avezado cazador, y su estrategia, muy similar a la utilizada en la caza de algunas aves, como la perdiz o la codorniz, se extiende a lo largo de varias octavas: desde la XXIX a la XXXVIII. El cazador coloca un reclamo: una hembra enjaulada, cuyo canto atrae al macho; Acis despliega toda su astucia en la disposición, a modo de cebo, de las ofrendas, preparadas con sumo cuidado, que resultarán ser extraordinariamente eficaces, pues atraen, por su delicadeza, el interés de la nereida (habida cuenta, además, de que quien las ofrece no la acosa). Son "de cortesía no pequeño / indicio", que no cabe atribuir ni al cíclope, ni "a sátiro lascivo, ni a otro feo / morador de las selvas". A continuación ha de esconderse, como hacen los cazadores. El reclamo ha cumplido su función, y es en este momento, justamente (octava XXX), cuando Cupido anticipa la victoria. En tanto la presa descubre el cebo ("entra al reclamo", en términos cinegéticos) y se muestra cada vez más confiada ("más discursiva y menos alterada"), el cazador sigue silenciosa y sigilosamente oculto, inmóvil, al acecho en el aguardo (esto es cabalmente lo que pretende Acis fingiendo dormir, en espera de que Galatea se aproxime). Poco a poco, a la par de los lentos movimientos que inicia para acercarse al cazador, la ninfa va perdiendo su condición de "monstro de rigor, de fiera brava" (y no es casual, tampoco, la identificación de Galatea con una "fiera"), va mirando la ofrenda "ya con más cuidado" y lamentando no encontrar a su dueño. La curiosidad primero y el interés después la van atrayendo hasta el muchacho, contemplándolo ("librada en un pie toda sobre él pende, de sitio mejorada...”), admirándolo, hasta que bebe lo más dulce del veneno del Amor y apura su ponzoña. Acis, Argos en su "sueño vigilante", solo cuando tiene a su alcance a la presa sacude su falso sueño y se abalanza a besar los pies de Galatea. El silencio del muchacho, aliado con el ocultamiento que Favonio propició, rinde más beneficios que la ostentosa desmesura del cíclope y su voz estentórea. El "fingir sueño", como indica Poppenberg, "es justo la estrategia de seducción de Acis. Así, lo erótico y lo poético conforman una correspondencia en el campo del fingir y de lo ficticio" 46.

157-263.

46 Gerhard Poppenberg, op. cit., p. 238. 
Que Góngora tenía presente la imagen cinegética se anunciaba ya desde el primer verso de la estrofa XXV: el mismo Acis (cuyo nombre puede remitir a un tipo de arma de $\mathrm{caza}^{47}$ ) aparece como un instrumento cinegético de Cupido, un "venablo"; más adelante, en las estrofas XXXIII y XXXIV, será la ninfa la que crea acechar, como un águila ${ }^{48}$, a Acis, para resultar engañada, sorprendida (a pesar de que la reacción de Acis era previsible) y asaltada ella misma ("salteada") por el cazador en la XXXVIII ${ }^{49}$.

La victoria ocupa las estrofas XL, XLI y XLII; pero, al igual que en la caza de la perdiz, el amor va irremediablemente ligado a la muerte, como desde el mismo tálamo anuncian las violas negras que, en la epitalámica lluvia de flores, caen sobre el infortunado Acis. Eros y thanatos se configuran así como elementos constitutivos del paisaje de la Arcadia, que, "en tanto que país del amor y de la poesía, será también el país de la muerte", consecuencia del engaño, de los celos y de un desdichado idilio ${ }^{50}$.

Góngora, pues, funde dos imágenes amorosas, la de la batalla y la de la caza, que no solo no son contradictorias, sino que se complementan, enriqueciendo la interpretación del texto. Y para ambas sirve la estampa de Cupido celebrando anticipadamente la victoria: el triunfo en la batalla y el cobro de la presa, habida cuenta de que Acis es, ante todo, un cazador $^{51}$. Del árbol pueden colgar los despojos tanto de la batalla como

47 Según la etimología propuesta por Andrés Cuesta, que discute Antonio Carreira, op. cit., pp. 52-53. Véase también al respecto los comentarios de Jesús Ponce Cárdenas, ed., Fábula de Polifemo y Galatea, pp. 257-258. Insiste en ello Gerhard Poppenberg, op. cit., p. 233: "Esto ya lo evidencia su nombre, que se remonta al término griego akis - 'punta, flecha'- y remite a su vez al latinismo acumen y al español agudeza. Como flecha de amor es también la punta (aguda) de un concepto poético y, por tanto, la figura de una vinculación de la erótica y de la poética”. No desdeña Poppenberg la connotación sensual del "venablo", que puede unirse al "áspid" y lo "viril del vulto" que descubre Galatea: juegos léxicos que bordean lo pornográfico y en los que Góngora no se preocupa por la "honesta oscuridad". Remito de nuevo a Gerhard Poppenberg, op. cit., pp. 219 y 233.

48 Imagen que a Gerhard Poppenberg, ibidem, pp. 239-240, le resulta "cetrera": es ahora Galatea quien parece iniciar una caza "de altanería", en tanto que, como un águila, observa a su presa desde arriba.

49 Véase Jesús Ponce Cárdenas (ed.), Luis de Góngora, Fábula de Polifemo y Galatea, pp. 257-258 y 284-286.

50 Gerhard Poppenberg, op. cit., pp. 213-214 y 216-217.

51 El propio Cupido aparece como cazador (si bien, irónicamente, del enamorado, 
de la caza, según las imágenes de la tradición clásica. La descripción de los restos de la pieza cobrada colgados de un árbol, al igual que tras la batalla las armas del enemigo, aparece también en la dedicatoria de las Soledades al duque de Béjar (“...y, en cuanto da el solícito montero / al duro robre, al pino levantado, / émulos vividores de las peñas, / las formidables señas / del oso que aún besaba, atravesado, / la asta de tu luciente jabalina...", vv. 16-21) y en otros lugares gongorinos (como el romance "Frescos airecillos") ${ }^{52}$.

Así pues, la mención del lecho y el ocultamiento sugerido y propiciado por Favonio pueden ser percibidos como un elemento fundamental en el desarrollo de la estratagema amorosa de Acis (y, por lo tanto, en la secuencia de la seducción), perdido en anteriores lecturas cinegéticas de la octava. La extrema precisión gongorina no podría haber obviado semejante paso. Por añadidura, ocupa su lugar exacto en la narración, manteniendo la focalización en Acis que se iniciaba en la octava XXIV (y que no cambia hasta la XXVIII) y permitiendo entender ahora la estrofa XXVII en perfecto paralelismo con la XXIII. Como explicaba Pozuelo, Góngora

que desea verse libre de su acoso) en Ovidio (Amores, 2, 9, 1-8). Véase José Antonio Bellido Díaz, "Desde Calímaco a Cervantes: una imagen venatoria en contexto amatorio", Anales Cervantinos, 40 (2008), pp. 133-143 (p. 137).

52 La imagen de los trofeos de caza colgados de un árbol goza de una amplia tradición desde Virgilio, Propercio y Ovidio. Una de las más antiguas referencias al respecto, según me hace notar el profesor Juan Martos, latinista, se localiza en los escolios a Aristófanes (Pluto, 943): "Era costumbre que los que habían cazado algún animal dejaran clavado un trozo de lo que habían atrapado, como la cabeza o las patas, en algún árbol del mismo bosque en honor a Artemis" (Juan Martos, ed., Apuleyo de Madauros, Apología o discurso sobre la magia en defensa propia. Floridas, Madrid, CSIC, 2016, p. 173, nota 523; Apuleyo recoge el motivo). En el escoliasta de Pluto encuentra también Pellicer, entre sus numerosas fuentes, la descripción del mismo rito en conmemoración de la batalla (José Pellicer, Lecciones solemnes, col. 198 bis). Aparece la celebración de la caza en Ovidio, Metamorfosis, XII, 266-267 (introducción y notas de A. Ramírez de Verger, traducción de A. Ramírez de Verger y F. Navarro Antolín, Madrid, Alianza, 1995): “[...] y toma por arma unas cuernas de ciervo / que estaban como exvoto en la copa de un pino". De Virgilio (Égloga VII, 29-30) y Propercio (Elegía II, 19, 17-20) lo toma Garcilaso (Égloga II, 188-196). Véase Lía Schwartz, "Las elegías de Propercio y sus lectores áureos", Edad de Oro, 24 (2005), pp. 323-350). Para las imágenes cinegéticas de Góngora, véase Rafael Bonilla Cerezo, op. cit., especialmente las pp. 201-202, en el caso de "Frescos airecillos". 
“anudó las secuencias de modo perfecto, no dejando resquicio alguno en la secuencia de los hechos y tasando mucho la transición de un estado a otro" 53 . Una vez más, se revela decisiva la precisión interpretativa de cada estrofa: en el fino trabajo de marquetería gongorino, cada pequeña pieza ocupa su lugar exacto para dar cuerpo y sentido al conjunto; en este caso, el lecho de hierba de Acis y las aéreas cortinas de Favonio completan la escena de la seducción y enriquecen el sentido de la Fábula al permitir la lectura de la secuencia en su conjunto no solo como una batalla amorosa, sino también como una "caza de amor".

53 José María Pozuelo Yvancos, op. cit, p. 438. 